\author{
Military Technical College \\ Kobry El-Kobbah, \\ Cairo, Egypt
}

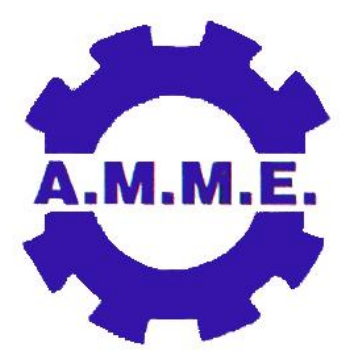

$14^{\text {th }}$ International Conference on Applied Mechanics and Mechanical Engineering.

\title{
Finite Element and Spectral Element Models of an Adaptive Magnetorheological Sandwich Beam
}

\author{
By \\ Peter L. Bishay ${ }^{\star} \quad$ Mohammad Tawfik* ${ }^{\star \star}$ Hani M. Negm ${ }^{\star \star *}$
}

\section{Abstract:}

The Magnetorheological fluid, as one of the smart materials, is the focus of many researches running nowadays and is getting to replace many materials in several engineering applications. This fluid is characterized by its ability to change from liquid into semi-solid gel in few milliseconds as a result of applying magnetic field.

This paper deals with a magnetorheological fluid embedded in an Aluminum sandwich beam to give the whole sandwich structure relevant controllability of various parameters such as natural frequencies, vibration amplitudes, and damping factors.

This paper presents Finite Element (FE) formulation of the MR sandwich beam, and uses the finite element model to solve for various beam boundary conditions, various magnetic field levels and configurations. The paper also compares the finite element results with published analytical results.

Finally, the paper checks the suitability of the spectral element (SE) method in dealing with the MR sandwich beam, and compares the spectral results with the finite element results.

\section{Keywords:}

Magnetorheological (MR) fluid, Sandwich beam, Finite element (FE), Spectral element (SE) 
* Teaching Assistant, Aerospace Engineering Department, Cairo University

** Assistant Professor, Aerospace Engineering Department, Cairo University

*** Professor Emeritus, Aerospace Engineering Department, Cairo University

\section{Introduction:}

Magnetorheological (MR) fluids belong to the class of controllable fluids. The essential characteristic of MR fluids is their ability to reversibly change from free-flowing, linear viscous liquids to semi-solids having controllable yield strength in milliseconds when exposed to a magnetic field. This yield stress increases with the applied magnetic field. This feature provides simple, quiet, rapid response interfaces between electronic controls and mechanical systems [1],[2].

These fluids are suspensions of micron-sized magnetic particles in an appropriate carrier liquid. There are different types of liquids which can be used as the carrier fluid i.e. hydrocarbon oils, mineral oils and silicon oils. Normally, MR fluids are free flowing liquids having a consistency similar to that of motor oil. However, in the presence of an applied magnetic field, the iron particles acquire a dipole moment aligned with the external field which causes particles to form linear chains parallel to the field. This phenomenon can solidify the suspended iron particles and restrict the fluid movement [3].

\subsection{Applications of MR fluids in adaptive sandwich beam structures}

Typically, MR adaptive structures are achieved by having MR material layers placed in solid metal or composite layers as shown in Figure (1). The dynamic response of the structure can be varied when different levels of magnetic field are applied over the MR layer, which in turn produce structures with variable stiffness and damping properties. These variations in the rheological properties of MR materials are fast (a few milliseconds) and reversible, in response to variations in applied magnetic field, and can manipulate the dynamic vibration responses of the composite quickly. By controlling the applied magnetic field, the vibration of the adaptive structures can be minimized for a broad range of external excitation frequencies.

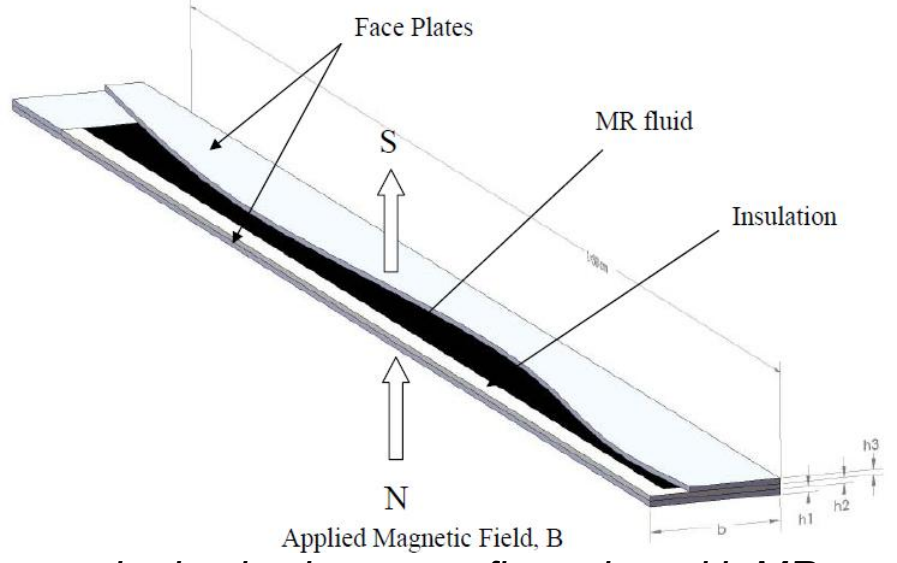

Figure (1): Three-layered adaptive beam configuration with MR material situated in the middle layer 
Yalcintas [4] turned to the MR sandwich beam problem after making a performance comparison between ER (Electrorheological) and MR sandwich beams. From that study it was observed that both $E R$ and MR adaptive structures show variations in their vibration responses when subjected to electric field and magnetic field respectively. These variations were mainly a decrease in both vibration amplitudes and loss factors, and an increase in the natural frequency when the electric/magnetic field is increased. However, variations were more significant for MR adaptive structures than for the ER adaptive structures.

Yalcintas and Dai [2], [5], followed by Sun et al. [6], developed a theoretical model for the MR sandwich beam and solved it only for the case of simply supported beams to predict its vibration response. Since the MR materials have higher stiffness values, the shear stresses experienced remain in the pre-yield regime. Therefore, the energy model considered in Yalcintas' study was based on the pre-yield rheological properties of MR materials.

Spectral analysis has been used for the approximate solution of different types of structural vibration problems. Doyle [7] used exponential interpolation functions with a wave length parameter that changes with the frequency for the bars and beams' finite element models that suit the nature of a structural dynamics problem.

Mahapatra et al.[8] presented a spectral finite element model for the study of composite beams. Wang and Wereley [9] presented a formulation for the application of spectral element analysis to a sandwich beam with a viscoelastic core. The spectral element method (SEM) provided much higher accuracy with a smaller number of elements as compared to the traditional finite element method.

In this paper, the modeling of a Magnetorhelolgical (MR) sandwich beam structure using the spectral element (SE) and the higher order finite element (FE) methods in structural analysis will be presented for the first time. The presence of the Finite Element model or the Spectral Element model for the MR sandwich beam made it possible and easy to consider other beam boundary conditions beside the Simply Supported beam which was the only available case for the analytical model developed previously by Yalcintas [5] and Sun [6]. The presence of the Finite Element model or the Spectral Element model made it possible to activate any portion of the MR sandwich beam with magnetic field.

\subsection{MR material rheological properties}

According to MR rheological studies, the shear stress-shear strain relation is analyzed in two regimes as pre-yield and post-yield regimes. These behaviors are illustrated in Figure (2). In the earlier studies, the MR pre-yield regime was modeled by a linear viscoelastic model, and the post-yield regime was modeled by the Bingham plastic model. Li et al [10] verified, through step-strain experiments, that the MR pre-yield behavior is linearly viscoelastic up to $0.1 \%$ shear strain, and nonlinear above the $0.1 \%$ shear strain.

In the three-layered sandwich beam configuration, the MR materials experience shear stress and shear strain that is confined in the pre-yield regime. Yalcintas [11] determined that the shear strain experienced by the MR layer is then below $0.1 \%$. Therefore, the linear viscoelastic theory is valid for MR adaptive structures. 


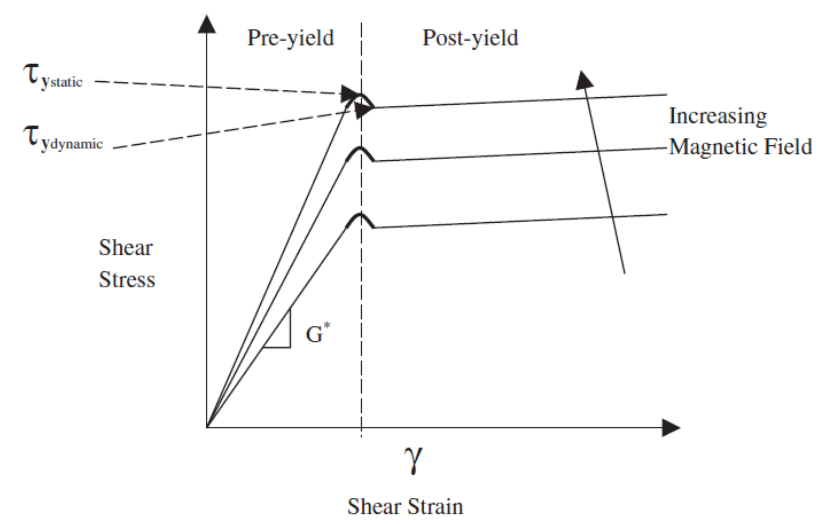

Figure (2): Shear stress -shear strain relationship of MR materials

\section{Finite Element and Spectral Element Modeling of the Three-Layer sandwich beam:}

In the following analysis we shall use Mead and Markus (MM) assumptions [12]:

a) The transverse displacement $(w)$ is the same for all the three layers.

b) Rotary inertia and shear deformations in the upper and lower elastic layer beams are negligible.

c) The Core layer has negligible bending stiffness and is subjected only to shear given by $\gamma_{z x}=\frac{\partial w}{\partial x}+\frac{\partial u}{\partial z}$

d) Linear theories of elasticity and viscoelasticity are valid.

e) No slip occurs between the layers, and there is perfect continuity at the interface.

f) All displacements are small.

The beam deformations are shown in Figure (3). A fundamental assumption of the approach is that line $\mathrm{B}-\mathrm{C}$ in the core layer remains straight after deformation, as shown by line $B^{\prime}-C^{\prime}$ in Figure (3). This, in effect, defines the axial deformation of any material position $(x)$ inside the core as a linear interpolation of the displacements $u_{1}^{\prime}$ and $u_{3}^{\prime}$ on the surfaces of the facesheets. 


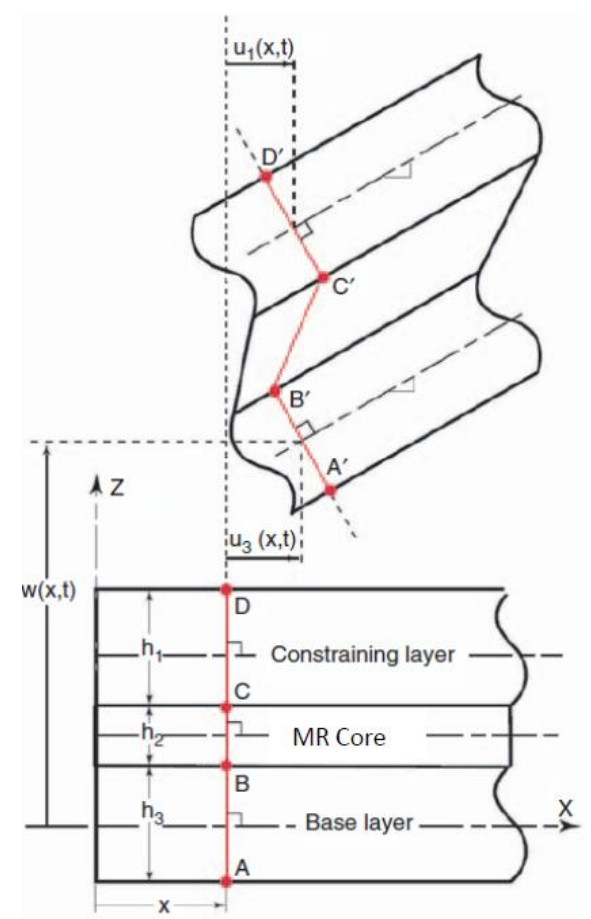

Figure (3): The undeformed (dashed line) and the deformed (Solid line) configurations of a three-layer sandwich beam under lateral loading

It can be proved that the axial displacement and the shear strain of the MR layer are given by [13]:

$u_{2}=\frac{u_{1}+u_{\mathrm{a}}}{2}+\frac{\boldsymbol{h}_{1}-\boldsymbol{h}_{\mathrm{a}}}{\mathbf{4}} \frac{\partial W}{\partial x}$

$\gamma_{z x}=\frac{u_{\mathbf{3}}-u_{1}}{h_{\mathbf{2}}}+\frac{d}{h_{\mathbf{2}}} \frac{\partial w}{\partial x}$

where $d=\frac{h_{1}}{2}+h_{2}+\frac{h_{3}}{2}$ is the distance between the reference lines of the undeformed facesheets.

Since the beam is assumed not subjected to longitudinal loading, the resultant of the longitudinal normal force must vanish, i.e.,

$E_{1} A_{1} \frac{\partial u_{1}}{\partial x}+E_{\mathrm{a}} A_{\mathrm{a}} \frac{\partial u_{\mathrm{a}}}{\partial x}=\mathbf{0}$

Integrating with respect to $x$ and expressing $u_{3}$ in terms of $u_{1}$, we have

$u_{\mathbf{3}}=-e u_{1}, \quad$ where $e=\frac{E_{1} A_{1}}{E_{3} A_{3}}$

Hence,

$u_{\mathbf{2}}=\frac{(1-e)}{2} u_{1}+\frac{\left(h_{\mathrm{a}}-\boldsymbol{h}_{\mathbf{1}}\right)}{4} \frac{\partial w}{\partial x}$ 
and $\gamma_{z x}=-\frac{(1+e)}{h_{\mathbf{z}}} u_{\mathbf{1}}+\frac{d}{\boldsymbol{h}_{\mathbf{2}}}\left(\frac{\partial w}{\partial x}\right)$

For simplicity, we will use " $u$ " instead of " $u_{\mathbf{1}}$ ".

\subsection{Development of the equations of motion:}

The equations of motion in this investigation are developed using Hamilton's principle:

$\delta\left(\int_{t_{1}}^{t_{2}}(T-U-V) d t\right)=0$

where $T$ is the kinetic energy, $U$ is the strain energy, and $V$ is the work done by external forces.

By taking the first variation, then integrating by parts with respect to time $\left(t_{1}\right.$ and $t_{2}$ are arbitrary), we get the weak form of Hamilton's principle, which is used for deriving the finite element equations of the system.

For the core layer, we may write:

$U_{\mathbf{z}}=\frac{1}{2} G_{\mathbf{z}} A_{\mathbf{2}} \int_{0}^{L} \gamma_{Z X}^{\mathbf{z}} d x$

$T_{2}=\frac{1}{2} \rho_{2} A_{2} \int_{0}^{L}\left(\frac{\partial u_{2}}{\partial t}\right)^{2} d x+\frac{1}{2} \rho_{2} A_{2} \int_{0}^{L}\left(\frac{\partial w}{\partial t}\right)^{2} d x$

where $G_{\mathbf{z}}$ is the complex shear modulus and $\gamma_{z x}$ is the shear strain. From the above, we may write:

$U_{2}=\frac{1}{2} G_{2} A_{2} \int_{0}^{L}\left(-\frac{(1+e)}{h_{2}} u+\frac{d}{h_{2}}\left(\frac{\partial w}{\partial x}\right)\right)^{2} d x$

$T_{\mathbf{z}}=\frac{1}{2} \rho_{\mathbf{z}} A_{\mathbf{z}} \int_{0}^{L}\left(\frac{\partial}{\partial t}\left(\frac{(1-e)}{2} u+\frac{\left(h_{3}-h_{1}\right)}{4} \frac{\partial w}{\partial x}\right)\right)^{2} d x+\frac{1}{2} \rho_{2} A_{2} \int_{0}^{L}\left(\frac{\partial w}{\partial t}\right)^{2} d x$

Using this, we may write the total energy as:

$U=\frac{1}{2}\left(E_{1} A_{1}+e^{2} E_{3} A_{3}\right) \int_{-6}^{L}\left(\frac{\partial u}{\partial x}\right)^{2} d x+\frac{1}{2}\left(E_{1} I_{1}+E_{3} I_{3}\right) \int_{0}^{L}\left(\frac{\partial^{2} w}{\partial x^{2}}\right)^{2} d x+$ 
$\frac{1}{2} G_{\mathbf{z}} A_{\mathbf{z}} \int_{0}^{L}\left[-\frac{(1+e)}{\boldsymbol{h}_{\mathbf{z}}} u+\frac{d}{\boldsymbol{h}_{\mathbf{z}}}\left(\frac{\partial w}{\partial x}\right)\right]^{\mathbf{z}} d x$

$T=\frac{1}{2}\left(\rho_{1} A_{1}+e^{2} \rho_{3} A_{3}\right) \int_{0}^{L}\left(\frac{\partial u}{\partial t}\right)^{2} d x+\frac{1}{2}\left(\rho_{1} A_{1}+\rho_{2} A_{2}+\rho_{3} A_{3}\right) \int_{0}^{L}\left(\frac{\partial w}{\partial t}\right)^{2} d x+$

$\frac{1}{2} \rho_{\mathbf{2}} A_{2} \int_{0}^{L} \frac{\partial}{\partial t}\left[\frac{(1-e)}{2} u+\frac{\left(h_{3}-h_{1}\right)}{4} \frac{\partial w}{\partial x}\right]^{2} d x$

\subsection{Finite Element Shape Functions}

In this paper, different beam models are used with different numbers of nodes. Also, the interpolation functions used are regular polynomials for the finite element and exponential functions for the spectral element.

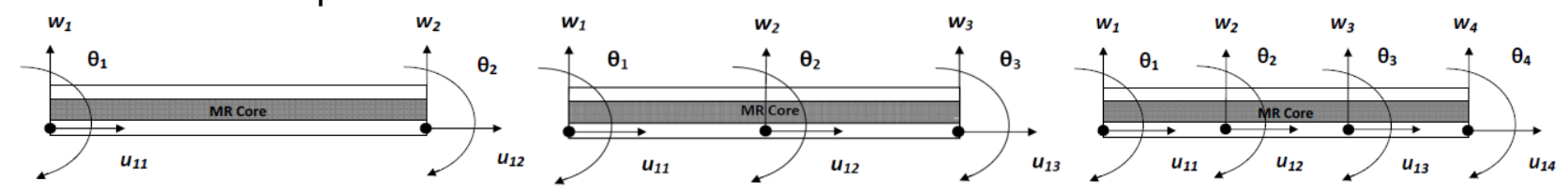

Figure (4): The proposed 2-node, 3-node, and 4-node sandwich beam elements with three degrees-of-freedom per node

The polynomial shape function for the longitudinal displacement $u(x)$ and the transverse deflection $w^{(x)}$ are:

$$
\begin{array}{ll}
u(x)=\sum_{0}^{n} a_{i} x^{i} & 0 \leq x \leq L \\
w(x)=\sum_{0}^{2 n} c_{i} x^{i} & 0 \leq x \leq L
\end{array}
$$

where $n$ is the number of nodes in the element.

For the spectral element (SE) model, the longitudinal displacement $u(x)$ and the transverse displacement $w(x)$ shape functions are:

$$
\begin{aligned}
& u(x)=a_{o} e^{i k_{u} x}+a_{1} e^{-i k_{u} x} \quad 0 \leq x \leq L \\
& W(x)=c_{O} e^{k_{W} x}+c_{1} e^{-k_{W} x}+c_{2} e^{i k_{W} x}+c_{3} e^{-i k_{W} x} \quad 0 \leq x \leq L
\end{aligned}
$$
the longitudinal wave speed and $D$ is the flexural rigidity of the beam. For the case of

Sandwich beam $C=\sqrt{\frac{E_{1} \text { [?] }}{\rho_{1}}} \quad, D=E_{1} I_{1}+E_{3} I_{3}$ and $k_{W}=\left(\frac{\omega^{2}\left(\rho_{1} h_{1}+\rho_{2} h_{2}+\rho_{3} h_{3}\right.}{D}\right)^{\frac{1}{4}}$ 


\subsection{Finite element model}

According to the normal procedure of the finite element method that could be found in any finite element textbook, we can rewrite the shape functions in the form:

$u(x)=\mathrm{L} N_{u} \mathrm{I}\left\{\delta_{u}\right\}$

$w(x)=\mathrm{I} N_{w} \mathrm{I}\left\{\delta_{w}\right\}$

where $\left\{\delta_{u}\right\}=\left\{\begin{array}{llll}u_{1} & u_{2} & \ldots & u_{n}\end{array}\right\}^{T}$

and $\mathbb{\square}\left\{\delta_{w}\right\}=\left\{w_{1_{1}} \& \theta_{1} \& w_{2} \& \theta_{2} \& \ldots \& W_{n} \& \theta_{n}\right\}^{T}$

Thus the element matrices may be written as:

$U=\frac{1}{2}\{\delta\}^{T}[K]\{\delta\}$

where $[K]=\left[K^{u}\right]+\left[K^{w}\right]+\left[K^{\gamma}\right]$,

$\left[K^{u}\right]=\left(E_{1} A_{1}+e^{z} E_{a} A_{a}\right) \int_{0}^{L}\left\{N_{u_{x}}\right\}\left[N_{u_{x}}\right] d x$,

$\left[K^{w}\right]=\left(E_{1} I_{1}+E_{\mathbf{a}} I_{\mathrm{a}}\right) \int_{0}^{L}\left\{N_{w_{x x}}\right\}\left[N_{w_{x x}}\right] d x$,

$\left[K^{\gamma}\right]=G_{\mathbf{z}} A_{\mathbf{2}} \int_{0}^{L}\left\{N_{\gamma}\right\}\left[N_{\gamma}\right] d x$.

$T=\frac{1}{2}\{\dot{\delta}\}^{T}[M][\delta]$

where $[M]=\left[M^{u}\right]+\left[M^{w}\right]+\left[M^{v}\right]$

$\left[M^{u}\right]=\left(\rho_{\mathbf{1}} A_{1}+e^{2} \rho_{\mathbf{a}} A_{\mathbf{a}}\right) \int_{0}^{L}\left\{N_{u}\right\}\left[N_{u}\right] d x$,

$\left[M^{w}\right]=\left(\rho_{1} A_{1}+\rho_{\mathbf{2}} A_{\mathbf{2}}+\rho_{\mathbf{3}} A_{\mathbf{a}}\right) \int_{0}^{L}\left\{N_{w}\right\}\left[N_{w}\right] d x$,

$\left[M^{v}\right]=\rho_{\mathbf{2}} A_{\mathbf{2}} \int_{0}^{L}\left\{N_{v}\right\}\left[N_{v}\right] d x$.

Finally, the element equation of motion becomes:

$[M]\{\bar{\delta}\}+[K]\{\delta\}=\{F\}$

$\{F\}$ is the external load vector, and will be set to zero during the free vibration analysis in order to get the natural frequencies of the MR sandwich beam.

A general MATLAB code for any-order element was developed to calculate the global mass and stiffness matrices for the MR sandwich beam, and hence calculate the natural frequencies and the loss factors for the MR sandwich beam for various beam boundary conditions. Another MATLAB code for the Spectral element was developed too. 


\section{Numerical Validation}

The developed mass and stiffness matrices for the sandwich beam elements with MRF core layer were used to calculate the natural frequencies and loss factors of an example beam Simply Supported from both ends with main dimensions and characteristics as in the paper of Yalcintas [5] for the sake of comparison with the analytical model and results found in this reference paper.

The main dimensions and properties of the MRF sandwich beam in [5] are as follows:

Beam length: $L=393.7 \mathrm{~mm}$, Beam width: $b=25.4 \mathrm{~mm}$,

Elastic Layers properties: Material: Aluminum, Elastic modulus: $\mathrm{E}=70 \mathrm{GPa}$, Density: $\rho=2700 \mathrm{Kg} / \mathrm{m}^{3}$,

Thickness: $\mathrm{h}_{1}=\mathrm{h}_{3}=0.7353 \mathrm{~mm}$

MR layer properties: Complex shear modulus: $G_{1} 2(B)=G^{x}(B)+G^{\prime \prime}(B) i$

where: $G^{\prime}(B)=3.11 \times 10^{-7} B^{2}+3.56 \times 10^{-4} B+5.78 \times 10^{-1}$, $G^{\prime \prime}(B)=3.47 \times \mathbb{R} 10 \rrbracket^{\top}(-9) B^{\top} 2+3.85 \times \llbracket 10 \rrbracket^{\top}(-6) B+6.31 \times \llbracket 10 \rrbracket^{\top}(-3)$,

Sun's model[6])

Or, $G_{\mathbf{2}}(B)=\left(1.25 \times 10^{3}+i 1.375 \times 10^{1}\right) B$

with the value of $G_{2}$ with no applied magnetic field assumed as:

$$
G_{\mathbf{z}}(0)=(0.6125+i 0.0067375) \mathrm{MPa} \text { (for Yalcintas' model [5]). }
$$

where $B$ (Oersted) is the value of magnetic induction.

Density: $\rho=3500 \mathrm{Kg} / \mathrm{m}^{3}$, Thickness: $h_{2}=0.7353 \mathrm{~mm}$.

Table (1) and Table (2) show the numerical values of the first three natural frequencies and loss factors of the Simply Supported-Simply Supported (SS-SS) MR sandwich beam for several magnetic field levels. The tables present the analytical model results found in [5] and [6] together with the results obtained by our FE and SE models. The results were computed using 5 elements and then using 10 elements for the two-node, three-node and four-node elements' models in addition to the spectral element model. It was found that the four-node element model gives very accurate results for natural frequencies and loss factors of the (SSSS) MR sandwich beam with error less than $1 \%$ with a smaller number of elements (3-5 elements). The three-node element model follows in accuracy, and then the two-node element model; which could require 10-15 elements to give accurate results with error less than $1 \%$. The spectral element model in the sandwich beam application unexpectedly gave accuracy slightly more than that of the 2-node FE, but less than that of the higher order FE models. These results validate the correctness of the equations, matrices and computer codes of the suggested MR sandwich beam finite element and spectral element models.

Table (1): The numerical values of the first three natural frequencies of the (SS-SS) MR sandwich beam for several magnetic field levels and the error percent of each for the 2-node, 3-node, 4-node and spectral elements in comparison with the analytical results 


\begin{tabular}{|c|c|c|c|c|c|c|c|}
\hline & $\begin{array}{l}\text { Magnetic } \\
\text { Field(Oe) }\end{array}$ & $\begin{array}{c}\text { Mode } 1 \\
(\mathrm{~Hz})\end{array}$ & $\begin{array}{c}\text { Mode } 2 \\
(\mathrm{~Hz})\end{array}$ & $\begin{array}{c}\text { Mode } 3 \\
(\mathrm{~Hz})\end{array}$ & $\begin{array}{r}\text { Error \% } \\
\text { in Mode } \\
1\end{array}$ & $\begin{array}{r}\text { Error \% } \\
\text { in Mode } \\
2\end{array}$ & $\begin{array}{r}\text { Error \% } \\
\text { in Mode } \\
3\end{array}$ \\
\hline \multirow{3}{*}{$\begin{array}{l}\text { Analytic } \\
\text { model }\end{array}$} & 0 & 19.1881 & 53.4212 & 98.514 & & & \\
\hline & 1000 & 23.7811 & 63.6707 & 115.086 & & & \\
\hline & 2000 & 25.7686 & 77.1646 & 138.578 & & & \\
\hline \multirow{3}{*}{$\begin{array}{l}\text { 2-node } \\
\text { (5 elements) }\end{array}$} & 0 & 19.2737 & 53.6763 & 99.2903 & 0.4463 & 0.4865 & 0.788 \\
\hline & 1000 & 23.9466 & 64.3061 & 116.4355 & 0.7262 & 0.9978 & 1.1726 \\
\hline & 2000 & 26.0278 & 78.5874 & 141.5051 & 1.0057 & 1.8438 & 3.1123 \\
\hline \multirow{3}{*}{$\begin{array}{l}\text { 3-node } \\
\text { ( } 5 \text { elements) }\end{array}$} & 0 & 19.1886 & 53.4268 & 98.5305 & 0.0028 & 0.0107 & 0.0168 \\
\hline & 1000 & 23.7821 & 63.6862 & 115.1386 & 0.0045 & 0.0243 & 0.0457 \\
\hline & 2000 & 25.7702 & 77.1998 & 138.7219 & 0.0061 & 0.0456 & 0.1038 \\
\hline \multirow{3}{*}{$\begin{array}{l}\text { 4-node } \\
\text { (5 elements) }\end{array}$} & 0 & 19.188 & 53.4212 & 98.5144 & 0.0001 & 0.0001 & 0.0004 \\
\hline & 1000 & 23.7811 & 63.6708 & 115.0873 & 0.0003 & 0.0001 & 0.0011 \\
\hline & 2000 & 25.7685 & 77.1646 & 138.5812 & 0.0005 & 0 & 0.0023 \\
\hline \multirow{3}{*}{$\begin{array}{l}\text { Spectral } \\
\text { (5 elements) }\end{array}$} & 0 & 19.2736 & 53.6717 & 99.2494 & 0.4457 & 0.4778 & 0.7465 \\
\hline & 1000 & 23.9464 & 64.3001 & 116.3854 & 0.7256 & 0.9885 & 1.129 \\
\hline & 2000 & 26.0276 & 78.5791 & 141.4382 & 1.0049 & 1.8332 & 3.064 \\
\hline \multirow{3}{*}{\begin{tabular}{|l}
2 -node \\
$(10$ \\
elements)
\end{tabular}} & 0 & 19.2094 & 53.479 & 98.6209 & 0.1111 & 0.1103 & 0.1084 \\
\hline & 1000 & 23.8222 & 63.8253 & 115.353 & 0.1801 & 0.2428 & 0.232 \\
\hline & 2000 & 25.8324 & 77.5143 & 139.2578 & 0.2477 & 0.4532 & 0.4905 \\
\hline \multirow{3}{*}{$\begin{array}{l}\text { 3-node } \\
\text { (10 } \\
\text { elements) }\end{array}$} & 0 & 19.1881 & 53.4215 & 98.5151 & 0.0001 & 0.0006 & 0.0011 \\
\hline & 1000 & 23.7811 & 63.6716 & 115.0895 & 0.0001 & 0.0014 & 0.003 \\
\hline & 2000 & 25.7686 & 77.1665 & 138.5872 & 0.0001 & 0.0025 & 0.0066 \\
\hline \multirow{3}{*}{$\begin{array}{l}\text { 4-node } \\
\text { (10 } \\
\text { elements) }\end{array}$} & 0 & 19.188 & 53.4212 & 98.514 & 0.0001 & 0.0001 & 0 \\
\hline & 1000 & 23.7811 & 63.6706 & 115.086 & 0.0003 & 0.0002 & 0.0001 \\
\hline & 2000 & 25.7685 & 77.1642 & 138.5776 & 0.0005 & 0.0005 & 0.0003 \\
\hline \multirow{3}{*}{$\begin{array}{l}\text { Spectral } \\
\text { (10 } \\
\text { elements) }\end{array}$} & 0 & 19.2094 & 53.4787 & 98.6182 & 0.1111 & 0.1097 & 0.1057 \\
\hline & 1000 & 23.8222 & 63.825 & 115.3499 & 0.1801 & 0.2423 & 0.2292 \\
\hline & 2000 & 25.8324 & 77.5138 & 139.2539 & 0.2476 & 0.4526 & 0.4877 \\
\hline
\end{tabular}

Table (2): The numerical values of the first three loss factors of the (SS-SS) MR sandwich beam for several magnetic field levels and the error percent of each for the 2-node, 3-node, 4-node and spectral elements in comparison with the analytical results

\begin{tabular}{|l|c|r|r|r|r|r|r|}
\hline & $\begin{array}{r}\text { Magnetic } \\
\text { Field(Oe) }\end{array}$ & $\begin{array}{r}\text { Mode } \\
1\end{array}$ & Mode 2 & Mode 3 & $\begin{array}{r}\text { Error \% } \\
\text { in Mode } \\
1\end{array}$ & $\begin{array}{r}\text { Error \% } \\
\text { in Mode } \\
2\end{array}$ & $\begin{array}{r}\text { Error \% } \\
\text { in Mode } \\
3\end{array}$ \\
\hline \multirow{2}{*}{$\begin{array}{l}\text { Analytic } \\
\text { model }\end{array}$} & 0 & 0.0058 & 0.0056 & 0.0041 & & & \\
& 1000 & 0.0046 & 0.0062 & 0.0055 & & & \\
\hline $\begin{array}{l}\text { 2-node } \\
\text { (5 elements) }\end{array}$ & 2000 & 0.0032 & 0.0058 & 0.0062 & & & \\
\hline & 1000 & 0.0059 & 0.0057 & 0.0041 & 1.3321 & 1.9242 & 1.4468 \\
\hline $\begin{array}{l}\text { 3-node } \\
\text { (5 elements) }\end{array}$ & 1000 & 0.0033 & 0.0064 & 0.0057 & 1.949 & 3.3754 & 3.5076 \\
\hline & 2000 & 0.0058 & 0.0056 & 0.0066 & 35.876 & 5.4421 & 6.5991 \\
\hline 4-node & 0 & 0.0032 & 0.0056 & 0.0041 & 0.0081 & 0.0532 & 0.1365 \\
\hline
\end{tabular}




\begin{tabular}{|l|c|c|c|c|c|c|c|}
\hline \multirow{2}{*}{ (5 elements) } & 1000 & 0.0046 & 0.0062 & 0.0055 & 0.0012 & 0 & 0.0054 \\
\cline { 2 - 7 } & 2000 & 0.0032 & 0.0058 & 0.0062 & 0.0021 & 0.0009 & 0.0082 \\
\hline Spectral & 0 & 0.0059 & 0.0057 & 0.0041 & 1.333 & 1.9395 & 1.5194 \\
\cline { 2 - 7 } (5 elements) & 1000 & 0.0047 & 0.0064 & 0.0057 & 1.9495 & 3.3894 & 3.5783 \\
\cline { 2 - 8 } 2-node & 2000 & 0.0033 & 0.0061 & 0.0066 & 3.5872 & 5.4528 & 6.6645 \\
\cline { 2 - 8 } (10 & 0 & 0.0058 & 0.0056 & 0.0041 & 0.3318 & 0.5155 & 0.5588 \\
\hline elements) & 2000 & 0.0046 & 0.0062 & 0.0055 & 0.479 & 0.8638 & 1.0412 \\
\hline 3-node & 0 & 0.0032 & 0.0058 & 0.0062 & 0.6227 & 1.3464 & 1.7682 \\
(10 & 1000 & 0.0058 & 0.0056 & 0.0041 & 0 & 0.0031 & 0.0089 \\
elements) & 2000 & 0.0032 & 0.0062 & 0.0055 & 0.0005 & 0.0047 & 0.0153 \\
\hline 4-node & 0 & 0.0058 & 0.0056 & 0.0062 & 0.0011 & 0.0064 & 0.0245 \\
\hline (10 & 1000 & 0.0046 & 0.0062 & 0.0055 & 0.0005 & 0.0031 & 0.0089 \\
elements) & 2000 & 0.0032 & 0.0058 & 0.0062 & 0.0011 & 0.0064 & 0.0153 \\
\hline Spectral & 0 & 0.0059 & 0.0056 & 0.0041 & 0.3319 & 0.5165 & 0.0245 \\
\hline (10 & 1000 & 0.0047 & 0.0063 & 0.0055 & 0.479 & 0.8648 & 1.0463 \\
elements) & 2000 & 0.0032 & 0.0059 & 0.0063 & 0.6228 & 1.3472 & 1.773 \\
\hline
\end{tabular}

The tables also show the effect of the magnetic field on the natural frequencies and loss factors of the (SS-SS) beam. The natural frequencies shift to higher frequencies as the applied magnetic field increases. These variations are observed more significantly at higher frequencies. The loss factor decreases at the first mode and increases at higher modes as the magnetic field strength increases.

This type of response of MR adaptive beams is a strong evidence of the control capabilities of MR materials in adaptive structures.

\section{Applications of the FEM on the MR sandwich beams}

The presence of the Finite Element model or the Spectral Element model for the MR sandwich beam makes it possible and easy to consider other beam boundary conditions beside the Simply Supported beam which was the only available case for the analytical model developed previously by Yalcintas [5] and Sun [6]. The presence of the Finite Element model or the Spectral Element model makes it possible to activate any portion of the MR sandwich beam with magnetic field, while deactivating the rest of the beam.

A MATLAB code has been developed to calculate the natural frequencies and loss factors for any-order-FE model or SE model for four kinds of MR sandwich beam boundary conditions which are: SS-SS, Fixed- Free, Fixed-SS, and Fixed- Fixed.

Application (1), given below, presents the natural frequencies of the MR sandwich beam with several boundary conditions, while Application (2) deals with certain effective portions of SSSS beam. The MR sandwich beam dimensions and properties used in these applications are similar to those found in Sun's paper [6].

\section{Application (1):}

In this application we calculate the natural frequencies for the first five modes of several kinds of beam boundary conditions at different magnetic field levels. These results can't all be obtained using the analytical model derived in the papers of Yalcintas [5] and Sun [6]. For the 
sake of high accuracy, we used 20 elements of the three-node type.

Table (3): Numerical results of the first three natural frequencies of the MR sandwich beam with several kinds of boundary conditions at various magnetic field levels

\begin{tabular}{|c|c|c|c|c|}
\hline \multirow{2}{*}{ B.C. type } & \multirow{2}{*}{$\begin{array}{l}\text { Mag. Field } \\
\text { (Oe) }\end{array}$} & \multicolumn{3}{|c|}{ Natural Frequencies $(\mathrm{Hz})$} \\
\hline & & Mode 1 & Mode 2 & Mode 3 \\
\hline \multirow{3}{*}{ SS-SS } & 0 & 20.9932 & 59.1363 & 116.6269 \\
\hline & 1000 & 25.9232 & 70.7952 & 131.9057 \\
\hline & 2000 & 30.54 & 86.1789 & 155.1905 \\
\hline \multirow{3}{*}{ Fixed-Free } & 0 & 9.7745 & 38.5946 & 87.5442 \\
\hline & 1000 & 11.3189 & 45.8463 & 101.5695 \\
\hline & 2000 & 12.4823 & 54.2412 & 120.3411 \\
\hline \multirow{3}{*}{ Fixed-SS } & 0 & 26.2954 & 69.564 & 132.7657 \\
\hline & 1000 & 32.0094 & 80.8011 & 147.2353 \\
\hline & 2000 & 38.6297 & 96.5068 & 169.9328 \\
\hline \multirow{3}{*}{ Fixed-Fixed } & 0 & 33.1945 & 81.4439 & 150.4351 \\
\hline & 1000 & 39.4622 & 91.9943 & 164.0862 \\
\hline & 2000 & 47.6956 & 107.5344 & 186.0359 \\
\hline
\end{tabular}

Table (3) presents the values of the first three natural frequencies for various MR sandwich beam boundary conditions at several magnetic field levels.

It is clear from the previous table that the effect of the magnetic field on the natural frequencies of the MR sandwich beam becomes more significant as the boundaries of the beam become more rigid i.e. the effect on the Fixed-Fixed natural frequencies is more than that on the Fixed-SS, Fixed-Free, and SS-SS natural frequencies. It is also clear that the effect of the magnetic field on the natural frequencies of the MR sandwich beam is more significant at higher modes.

\section{Application (2):}

From equation (2), it is clear that the shear strain of the MR layer depends on two factors: the relative axial displacement between the upper and lower layers, and the slope of the transverse displacement. Hence, for each beam boundary condition, each mode shape has some parts of the beam span that have more curvature than other parts. If these parts only are activated with the magnetic field, they will give almost the same targeted natural frequencies as those of the totally activated MR sandwich beam. To illustrate this, we use a SS-SS MR sandwich beam made up of 30 elements. For the sake of accuracy the elements' model will be of the three-node type. The applied magnetic field on the beam is 2000 Oe. Targeting the first three natural frequencies, we will use three activation configurations as shown in Figure (5).

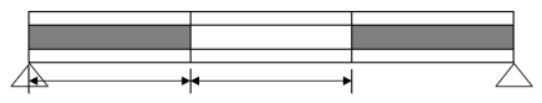

A

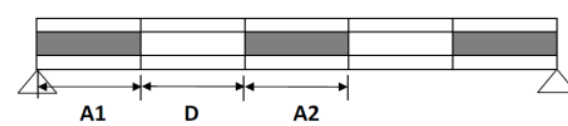

Figure (5): The proposed activation configurations to target the first three modes of the SSSS MR sandwich beam 
Table (4), Table (5), and Table (6) compare the natural frequencies of the fully activated and fully deactivated beams with the three proposed activation configurations for the SS-SS MR sandwich beam with several lengths of the activated portions. In these tables, "A" refers to the activated length, while " $D$ " refers to the deactivated length. Note that the activation pattern is symmetric about the beam mid-span.

It can be seen from Table (4) that with deactivation of almost half the beam length, the fundamental natural frequency is decreased by only $5 \%$ from the case of the fully activated MR sandwich beam (case 3 or 4).

Note that even in the first case where the deactivated portion is only one third of the total beam length and where the fundamental natural frequency is $98.7 \%$ from that of the fully activated one, the second natural frequency of this case is far from that of the fully activated one. This is because the proposed configuration is targeting the first mode only.

Table (4): Comparison of the first activation configuration with its different cases with the fully activated SS-SS MR sandwich beam

\begin{tabular}{|c|c|c|c|c|c|c|c|}
\hline & $\begin{array}{l}\text { Mode } 1 \\
(\mathrm{~Hz})\end{array}$ & \multirow{2}{*}{$\begin{array}{l}\% \text { from fully } \\
\text { activated } 1^{\text {st }} \\
\text { natural freq. }\end{array}$} & $\begin{array}{l}\begin{array}{l}\text { Mode } 2 \\
(\mathrm{~Hz})\end{array} \\
\end{array}$ & $\begin{array}{l}\text { Mode } 3 \\
(\mathrm{~Hz})\end{array}$ \\
\hline \multicolumn{4}{|c|}{ Fully Activated } & 30.54 & & 86.1789 & 155.1902 \\
\hline Case & A & $\mathrm{D}$ & $\%$ Active & & & & \\
\hline 1 & $0.33 \mathrm{~L}$ & $0.33 \mathrm{~L}$ & $66 \%$ & 30.1419 & 98. & 69.8046 & 141.693 \\
\hline 2 & $0.3 \mathrm{~L}$ & $0.4 \mathrm{~L}$ & $60 \%$ & 29.8181 & $97.64 \%$ & 68.2308 & 136.3095 \\
\hline 3 & $0.27 \mathrm{~L}$ & $0.46 \mathrm{~L}$ & $54 \%$ & 29.3594 & $96.13 \%$ & 67.3487 & 131.9837 \\
\hline 4 & $0.23 \mathrm{~L}$ & $0.54 \mathrm{~L}$ & $46 \%$ & 28.761 & $94.17 \%$ & 66.9819 & 129.1804 \\
\hline 5 & $0.2 \mathrm{~L}$ & $0.6 \mathrm{~L}$ & $40 \%$ & 28.0326 & $91.79 \%$ & 66.9116 & 127.8563 \\
\hline \multicolumn{4}{|c|}{ Fully Deactivated } & 20.9932 & & 59.1363 & 116.6269 \\
\hline
\end{tabular}

It can be seen from Table (5) that with deactivation of almost $40 \%$ of the beam length, the second natural frequency is decreased by only $2.8 \%$ from the case of the fully activated MR sandwich beam (case 1 or 2), and with deactivation of almost $47 \%$ of the beam length, the second natural frequency is decreased by only $4 \%$ from the case of the fully activated MR sandwich beam (case 3).

Note that from the four cases of this configuration, the fourth case was the worst with respect to the second natural frequency, but it is the best with respect to the fundamental frequency, this is because this case is similar to the fifth case in the first configuration which was targeting the fundamental natural frequency with $0.2 \mathrm{~L}$ activated portion near each SS end. Note also that even in the first case where the deactivated portion is only $40 \%$ of the total beam length and where the second natural frequency is $97.17 \%$ from that of the fully activated one, the third natural frequency of this case is far from that of the fully activated one. This is because the proposed configuration is targeting the second mode only.

Table (5): Comparison of the second activation configuration with its different cases with the fully activated SS-SS MR sandwich beam

\begin{tabular}{|l|c|c|c|l|}
\hline & $\begin{array}{c}\text { Mode 1 } \\
(\mathrm{Hz})\end{array}$ & $\begin{array}{c}\text { Mode 2 } \\
(\mathrm{Hz})\end{array}$ & $\begin{array}{c}\text { \% from fully } \\
\text { activated 2 }\end{array}$ & Mode 3 $(\mathrm{Hz})$ \\
\hline
\end{tabular}




\begin{tabular}{|c|c|c|c|c|c|c|c|c|}
\hline \multicolumn{5}{|c|}{ Fully Activated } & 30.54 & 86.1789 & natural freq. & 155.1902 \\
\hline Case & A1 & D & A2 & $\begin{array}{c}\% \\
\text { Active }\end{array}$ & & & & \\
\hline 1 & $0.13 \mathrm{~L}$ & $0.2 \mathrm{~L}$ & $0.33 \mathrm{~L}$ & $60 \%$ & 27.1545 & 83.7372 & $97.17 \%$ & 141.7568 \\
\hline 2 & $0.17 \mathrm{~L}$ & $0.2 \mathrm{~L}$ & $0.27 \mathrm{~L}$ & $60 \%$ & 27.7025 & 83.7372 & $97.17 \%$ & 136.5902 \\
\hline 3 & $0.13 \mathrm{~L}$ & $0.23 \mathrm{~L}$ & $0.27 \mathrm{~L}$ & $53 \%$ & 26.7895 & 82.7023 & $96 \%$ & 136.536 \\
\hline 4 & $0.2 \mathrm{~L}$ & $0.2 \mathrm{~L}$ & $0.2 \mathrm{~L}$ & $60 \%$ & 28.2683 & 81.8466 & $95 \%$ & 132.5573 \\
\hline \multicolumn{5}{|c|}{ Fully Deactivated } & 20.9932 & 59.1363 & & 116.6269 \\
\hline
\end{tabular}

It can be seen from Table (6) that with deactivation of almost $40 \%$ of the beam length, the third natural frequency is decreased by only $3.2 \%$ from the case of the fully activated MR sandwich beam (case 4), and with deactivation of almost $46 \%$ of the beam length, the third natural frequency is decreased by only $6 \%$ (case 5 ).

As a final conclusion, with only $60 \%$ activated beam span we can target any mode by placing the activated portions in the proper places to get the effect of the fully activated MR sandwich beam at this mode.

Table (6): Comparison of the third activation configuration with its different cases with the fully activated SS-SS MR sandwich beam

\begin{tabular}{|c|c|c|c|c|c|c|c|c|c|}
\hline \multirow{2}{*}{\multicolumn{6}{|c|}{ Fully Activated }} & Mode 1 & Mode 2 & Mode 3 & \multirow{3}{*}{$\begin{array}{l}\% \text { from fully } \\
\text { activated } 2^{\text {nd }} \\
\text { natural free. }\end{array}$} \\
\hline & & & & & & \multirow[t]{2}{*}{30.54} & \multirow[t]{2}{*}{86.1789} & \multirow{2}{*}{155.1902} & \\
\hline Case & A1 & D1 & A2 & D2 & $\begin{array}{l}\% \\
\text { Active }\end{array}$ & & & & \\
\hline 1 & $0.13 \mathrm{~L}$ & $0.07 \mathrm{~L}$ & $0.23 \mathrm{~L}$ & $0.13 \mathrm{~L}$ & $73 \%$ & 28.7358 & 81.321 & 153.768 & $99 \%$ \\
\hline 2 & $0.13 \mathrm{~L}$ & $0.1 \mathrm{~L}$ & $0.2 \mathrm{~L}$ & $0.13 \mathrm{~L}$ & $67 \%$ & 28.7174 & 77.7586 & 152.8231 & $98.4 \%$ \\
\hline 3 & $0.13 \mathrm{~L}$ & $0.13 \mathrm{~L}$ & $0.2 \mathrm{~L}$ & $0.07 \mathrm{~L}$ & $67 \%$ & 28.1426 & 81.2749 & 151.1431 & $97.4 \%$ \\
\hline 4 & $0.13 \mathrm{~L}$ & $0.13 \mathrm{~L}$ & $0.17 \mathrm{~L}$ & $0.13 \mathrm{~L}$ & $60 \%$ & 28.1223 & \begin{tabular}{|l|}
77.7311 \\
\end{tabular} & 150.2472 & $96.8 \%$ \\
\hline 5 & $0.13 \mathrm{~L}$ & $0.17 \mathrm{~L}$ & $0.13 \mathrm{~L}$ & $0.13 \mathrm{~L}$ & $53 \%$ & 27.584 & 77.6481 & 146.0131 & $94.08 \%$ \\
\hline Fully & eactiv & ed & & & & 20.9932 & 59.1363 & 116.6269 & \\
\hline
\end{tabular}

\section{Conclusion}

In this paper we have developed a spectral and a higher order finite element models for the MR sandwich beam. The proposed models were used to perform free vibration analysis and calculate natural frequencies and loss factors of a MR sandwich beam. The results were compared with the analytical model results published previously. It was shown that the 4node element model gives the highest accuracy with a small number of elements.

Then we used the developed models in two applications, the first was investigating the dynamic characteristics of different MR sandwich beam boundary conditions that were unavailable in the previous analytical models. The second was investigating the critical parts to be activated on the beam span to get the natural frequencies of the fully activated MR sandwich beam. In this application we have proposed several activation configurations in targeting the first, second and third natural frequencies of a SS-SS sandwich beam. We have shown that we can get the same effect of the fully activated MR sandwich beam by activating only $60 \%$ of the beam span at the proper parts for the targeted mode and the required boundary conditions.

\section{References}


[1] G.Yang, "Large-Scale Magnetorheological Fluid Damper for Vibration Mitigation: Modeling, Testing and Control," Ph.D dissertation, University of Notre Dame, 2001. http://cee.uiuc.edu/sstl/gyang2/ch2.pdf.

[2] A.G. Olabi and A. Grunwald, "Design and application of magneto-rheological fluid", Materials and Design 28 (2007) 2658-2664.

[3] J. David Carlson and Mark R. Jolly, "MR fluid, foam and elastomer devices", Mechatronics 10 (2000) 555-569.

[4] Melek Yalcintas and Heming Dai, "Magnetorheological and Electrorheological Materials in Adaptive Structures and their Performance Comparison", Smart Mater. Struct. 8 (1999) 560-573.

[5] Melek Yalcintas and Heming Dai, "Vibration Suppression Capabilities of Magnetorheological Materials Based Adaptive Structures", Smart Mater. Struct. 13 (2004) $1-11$.

[6] Qing Sun, Jin-Xiong Zhou, Ling Zhang, "An Adaptive Beam Model and Dynamic Characteristics of Magnetorheological Materials", Journal of Sound and Vibration 261 (2003) 465-481.

[7] Doyle, J. F., "Wave Propagation in Structures: Spectral Analysis Using Fast Discrete Fourier Transforms," Mechanical Engineering Series, $2^{\text {nd }}$ ed., Springer-Verlag, 1997.

[8] Mahapatra, D. R., Gopalakrishnan, S., and Sankar, T. S., "Spectral-Element-Based Solutions for Wave Propagation Analysis of Multiply Connected Unsymmetrical Laminated Composite Beams," Journal of Sound and Vibration, Vol. 237, No. 5, 2000, pp. 819-836.

[9] Wang, G. and Wereley, N. M., "Spectral Finite Element Analysis of Sandwich Beams with Passive Constrained Layer Damping," $40^{\text {th }}$ AIAA/ASME/ASCE/AHS/ASC Structures, Structural Dynamics, and Materials Conference and Exhibit, American Institute of Aeronautics and Astronautics, 1999, p. 2681-2694.

[10] Li WH, Du H, Chen G, Yeo S H and Guo N Q, "Nonlinear Rheological Behavior of Magnetorheological Fluids: Step-Strain Experiments", J. Smart Mater. Struct. 11 (2002) 209-17

[11] Melek Yalcintas, "An Analytical and Experimental Investigation of Electrorheological Material Based Bdaptive Structures", 1995, Dissertation Lehigh University.

[12] Mead D. J. and Markus S, "The forced vibration of a three layer damped sandwich beam with arbitrary boundary conditions", Journal of Sound and Vibration 10 (1969) 163-175.

[13] Jalil Rezaeepazhand and Lotfollah Pahlavan, "Transient Response of Sandwich Beams with Electrorheological Core", Journal of Intelligent Material Systems and Structures 2009; 20; 171. 